\title{
Predictability of locomotion: Effects on updating of spatial situation models during narrative comprehension
}

\author{
STEPHAN DUTKE \\ University of Kaiserslautern, Kaiserslautern, Germany \\ and \\ MIKE RINCK \\ Dresden University of Technology, Dresden, Germany
}

\begin{abstract}
We investigated how the updating of spatial situation models during narrative comprehension depends on the interaction of cognitive abilities and text characteristics. Participants with low verbal and visuospatial abilities and participants with high abilities read narratives in which the protagonist's motions in a fictitious building were either highly predictable or very hard to predict. In Experiment 1, high-ability readers updated spatial situation models only if the protagonist's motions were hard to predict, whereas low-ability readers did so only if the motions were highly predictable. In Experiment 2 , facilitated integrative spatial processing compensated for the low-ability participants' resource limitations. As a result, both ability groups updated spatial situation models with hard-to-predict protagonist motions. These results highlight the interactions of cognitive abilities and text characteristics in spatial situation model updating.
\end{abstract}

There is wide agreement in text comprehension research (Zwaan \& Radvansky, 1998) that understanding a text involves the construction of representations at different levels of processing (e.g., Gernsbacher, 1990; Graesser, Millis, \& Zwaan, 1997; Graesser, Singer, \& Trabasso, 1994; W. Kintsch, 1998; van Dijk \& W. Kintsch, 1983; Zwaan, Langston, \& Graesser, 1995). The representation of the text surface and the propositional representation of the text's meaning (text base, or text representation) represent features of the text itself, whereas the situation model, or mental model, represents aspects of the situation the text is referring to (Garnham \& Oakhill, 1996). Constructing a valid and coherent model of what the text is referring to is assumed to be a core process of understanding a text, in that the situation model integrates text information with the reader's world knowledge. Furthermore, most researchers agree that these constructive processes interact with representations of the pragmatic communicative context, text genre, reader's goals, and text quality (Graesser

This research was supported by Grants DU 312/1-1 and Ri 600/9-1 from the German Research Foundation (DFG) to the authors. We thank Katja Bender for conducting the experiments and preparing data analysis and the reviewers for helpful suggestions on an earlier version of the manuscript. M.R. is now at Radboud University Nijmegen, The Netherlands. Correspondence concerning this article should be addressed to S. Dutke, Department of Psychology, University of Kaiserslautern, Pfaffenbergstr. 95, D-67663 Kaiserslautern, Germany (e-mail: dutke@rhrk.uni-kl.de).

Note-This article was accepted by the previous editorial team, when Colin M. MacLeod was Editor. et al., 1997). Especially the latter factor produced some (at first glance) counterintuitive effects in that under specific circumstances, deficient expository texts led to a better understanding than did less deficient texts. For example, E. Kintsch (1990) reported that more knowledgeable and more skilled readers wrote better summaries of a poorly organized text than of a well-organized one. Presumably, reading a poorly organized text required more active processing for the text information to be integrated with the reader's background knowledge. A well-organized text might obviate this deep integration, however, in favor of a superficial understanding of the text (cf. Bereiter \& Scardamalia, 1989; Mannes \& W. Kintsch, 1987). Likewise, McNamara, E. Kintsch, Songer, and W. Kintsch (1996) found that high-knowledge eighth-grade readers benefited more from a minimally coherent version of an expository text than from a fully coherent version. McNamara and W. Kintsch (1996), as well as McNamara (2001), replicated these results for adult readers' comprehension of expository texts. They also provided evidence from reading times for the claim that lack of coherence forced highknowledge readers to engage in compensatory integration of world knowledge, in order to bridge coherence gaps. Depending on the difficulty of the texts, McNamara et al. (1996) and McNamara (2001) found beneficial effects of less coherent texts in tests that tapped either situation model information or text base information.

The present study was an attempt to extend this research in three directions. First, the above-mentioned studies compared "good" expository texts with "bad" ones. Narrative texts, however, are expected to be coherent, and usu- 
ally authors are motivated to avoid coherence gaps, except when they wish to produce specific effects, such as surprise or astonishment. Therefore, it would be informative to test whether the compensatory effects found by $\mathrm{McNa}$ mara and her colleagues also occur with narrative texts that differ in ease of processing, although they have the same degree of coherence. Second, the studies reported so far have been inconclusive regarding the question of whether the reader-text interaction affects comprehension at the text base level or the situation model level. Therefore, we chose to assess comprehension of information that could be located clearly at the situation model level. To this end, we used the well-established spatial distance effect described below, and we measured online reading times. Third, in the studies reported by McNamara and her colleagues, the reader's knowledge level contributed to the perceived complexity of the stimulus texts. The present study explores to what extent different levels of ability contribute to compensatory processes in situation model construction.

To address the first goal, short narratives were constructed. Each narrative described how a protagonist moved through a fictitious research center (see Figure 1), thereby executing various actions. Each narrative existed in two versions differing in one feature only. In one version, the protagonist moved through the building in the same, counterclockwise direction while he or she interacted with other people or dealt with various tasks. In this version, the protagonist's movements were easily anticipated, because he or she never changed direction while moving through the building. In the second version, the protagonist changed his or her direction from moving counterclockwise to moving clockwise through the building. In this version, the protag- onist's motions were harder to predict because he or she did not follow the simple schema of proceeding from one room to the next. The participants read either only narratives with or only narratives without change of direction. In the text versions with change of direction, the protagonist's motions should be harder to map than in the versions without change of direction. Nevertheless, the versions did not differ with regard to text coherence or contents (see the Method section below).

To address the second point, the anaphor method used in studies of the so-called spatial distance effect was adopted (e.g., Rinck \& Bower, 1995; Rinck, Hähnel, Bower, \& Glowalla, 1997; Rinck, Williams, Bower, \& Becker, 1996). In these studies, participants first learn the layout of a building containing several objects in different rooms (Figure 1). Afterward, they read narratives that describe a protagonist's actions and motions in this building. Socalled motion sentences describe how the protagonist moves through the building - for instance, "Wilbur walked from the reception room into the library." Some of these motion sentences are followed by an anaphoric target sentence that refers to an object located in the building by means of a definite noun phrase, such as "Wilbur thought that the desk still looked like an awful mess" (Rinck \& Bower, 1995, p. 110). Reading a definite noun phrase initiates a memory search for the referent of this phrase-in this case, "the desk." The anaphor referent is located (1) in the room the protagonist has just moved into (goal room), (2) in the room the protagonist has just passed through (path room), or (3) in the room the protagonist set off from (source room). Typically, reading times are found to be shorter for goal room sentences than for path room sen-

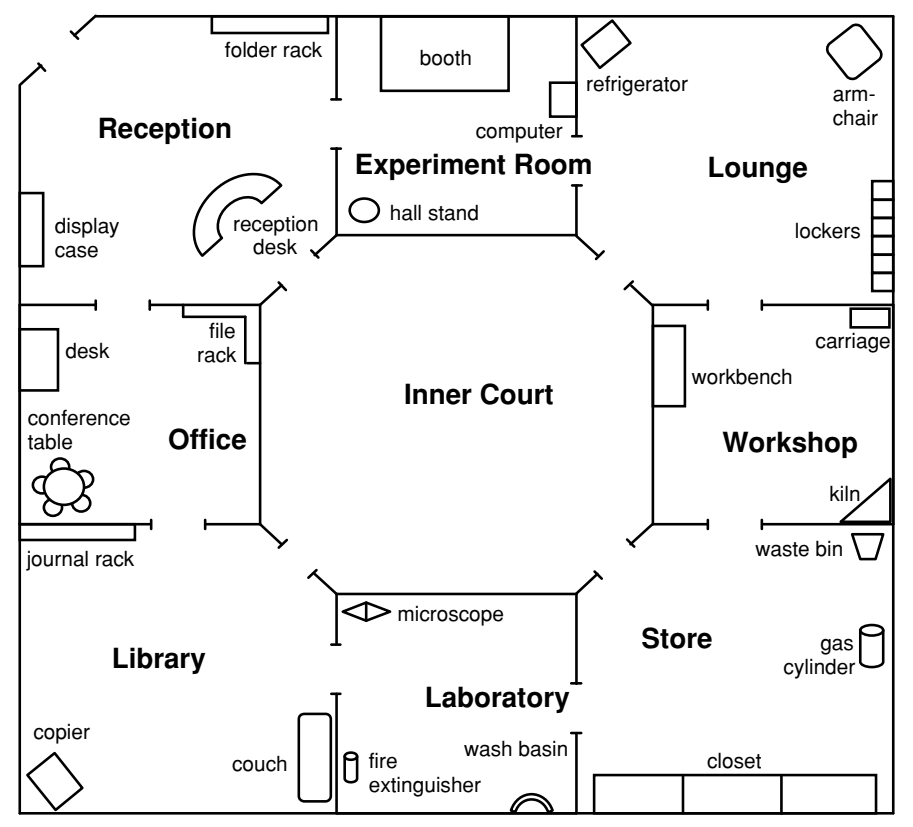

Figure 1. Layout of the fictitious research center in the with-changeof-direction condition. In the without-change-of-direction condition, the corner rooms had no doors to the inner courtyard. The layouts used in the experiment were labeled in German. 
tences, which, in turn, are read more quickly than source room sentences - a pattern that has become known as the spatial distance effect in situation models.

This reading time pattern suggests that the situation model (1) represents spatial attributes of the narrative's setting and (2) is more influential than the text representation (Dutke, 2003). The first part of the interpretation rests on the observed reading time pattern. The greater the spatial distance between the protagonist's current position and the location of the anaphor referent, the slower the target sentence is read-presumably, because the more distant the referent is from the reader's focus of attention, the less accessible it becomes. The second part of the interpretation rests on the combination of the motion sentence and the anaphoric noun phrase in the target sentence. Usually, the motion sentence is of the type "The protagonist moves from the [source room] into the [goal room]" and does not mention the path room that has to be crossed on the way from the source room to the goal room. Assuming that naming the room in which the referent is located (referent room) preactivates the relevant knowledge about the spatial setting, one should expect the time required to resolve the anaphor (i.e., to find the referent) to be a function of whether or not the name of the referent room is mentioned before the anaphor is read. Consequently, referents in the previously mentioned goal room and source room should be more accessible than referents in the unmentioned path room. In fact, however, the spatial distance effect documents a different pattern. Referents in path rooms are more accessible than objects in source rooms, although the more distant source room was explicitly mentioned in the motion sentence, whereas the closer path room was not. Thus, Dutke (2003) argued that the emergence of the spatial distance effect requires the situation model to be spatially organized and to be stronger than the surface and propositional representations, in that spatial distance appears to be a stronger determinant of anaphor resolution time than is priming the referent room by explicitly mentioning its name.

In the present study, the spatial distance effect paradigm was used as a tool to assess the relative strength of the situation model. If the protagonist's motions are hard to predict, the construction of a valid situation model requires spatial text information to be processed more precisely, and text information about the protagonist's route is harder to integrate into the current situation model than in texts in which the protagonist's motions are easy to predict. Because of this deeper processing, the situation model should be better organized and more easily available than in texts in which the protagonist's motions are more predictable. Thus, the spatial distance effect on anaphor resolution should be greater in texts with change of direction than in texts without change of direction. In contrast, when the protagonist's motions are highly predictable (such as in texts without change of direction), the spatial distance effect should be smaller, because the text base need not be as intensively integrated with spatial preknowledge to create a valid situation model.
The third goal addresses the role of individual differences. Recent studies have shown that readers differ considerably in terms of the abilities they need to construct and update situation models. For instance, reading abilities (Long, Oppy, \& Seely, 1997), visuospatial abilities (de Vega, 1994; Dutke, 1999; Haenggi, W. Kintsch, \& Gernsbacher, 1995), language proficiency (Zwaan \& Brown, 1996), and working memory capacity (Friedman \& Miyake, 2000; Shah \& Miyake, 1996) have been shown to affect the quality of situation models (but see Radvansky \& Copeland, 2001, 2004). In the context of the present study, readers have to have at their disposal both sufficient verbal and visuospatial abilities (Shah \& Miyake, 1996). Although none of the previous studies addressed predictability of protagonist motions directly, they suggest that individual variations in verbal and visuospatial abilities will affect integrative spatial processing. In particular, if sufficient abilities are available, reduced predictability should have the expected positive effect on integrative spatial processing. If, however, available abilities are insufficient, the relative strength of the situation model will not increase, since no increase in integrative processing is possible. Hence, the spatial distance effect will not increase in participants with limited abilities, but it will increase in participants who are able to invest additional resources. In the present study, we measured participants' verbal abilities, as well as their visuospatial abilities, because the former may be expected to affect completeness and coherence of the underlying propositional text base and the latter may be expected to affect the representation of spatial relationships in the situation model. The more pronounced these abilities are, the more the spatial distance effect may be expected to increase as a function of reduced spatial predictability.

\section{EXPERIMENT 1}

The first experiment was designed to test (1) whether the spatial distance effect increases when the protagonist's motions are less predictable, (2) whether this increase is more pronounced in individuals with higher verbal and visuospatial abilities than in those with lower abilities, and (3) whether verbal or visuospatial abilities are independent predictors of the effects of predictability on the spatial distance effect.

\begin{abstract}
Method

\section{Participants}

Forty-eight students (24 women) at the University of Kaiserslautern participated in this experiment. All the participants were native speakers of German or spoke German fluently. Their ages ranged from 18 to 32 years $(M=25)$. They received a payment of $€ 7.50$ for participating. In addition, they could earn a bonus of up to $€ 3$, depending on the number of comprehension questions answered correctly (see below).
\end{abstract}

\section{Materials}

Layouts. All the events described in the experimental narratives were situated in a fictitious research center, consisting of eight 
rooms surrounding an inner courtyard (see Figure 1). Except for the courtyard, each room contained three objects, such as a desk, a file rack, and a conference table. These objects were organized into three object sets, with each room containing one object from each of the three sets. Pretesting ensured that the objects in the three sets did not differ with regard to familiarity. The layout of the building and the experimental narratives were in German. For the participants who later read narratives in the with-change-of-direction condition, each corner room had a door connecting it to the courtyard. These doors did not exist in the layout version for the participants who were later presented with the no-change-of-direction narratives.

Narrative versions without change of direction. Each of the experimental narratives described a single protagonist moving through the research center along a certain path. The basic pattern of this movement consisted of the protagonist's starting off from a room on one side of the building (e.g., the experiment room) and moving counterclockwise through the next six rooms into the eighth room (e.g., the lounge), while working on various tasks (e.g., looking for someone). This basic pattern (see Figure 2, left panel) was rotated by $90^{\circ}$ three times, yielding four different movement patterns. For each of the four patterns, two narratives were created, each consisting of 18 sentences (for a sample text, see the Appendix). Each narrative contained two critical movements, each explicitly described in a critical motion sentence (e.g., "She then went from the reception into the library"), followed by a motion-irrelevant sentence (e.g., "There she stood still for a moment, waiting for any more noises"). An anaphoric target sentence followed, referring either to an object in the path room (path room sentence; e.g., "She thought she could hear a faint sound coming from the desk") or to an object in the source room (source room sentence; e.g., "She thought she could hear a faint sound coming from the display case"). The anaphor referent in 1 target sentence was taken from Object Set 1 and the other from Object Set 2, whereas objects from the third set were not used in any sentence. Thus, each of the eight narratives could appear in one of four versions resulting from a full combination of sequence of target sentences (path room sentence before or after source room sentence) and object used in the target sentence (from Set 1 or Set 2). The 32 text versions were organized into four sets of eight texts each, and the participants were randomly assigned to one of these sets, with the restriction that across the sample, all the text sets were used equally often in each experimental condition. Each text was followed by three yes-no comprehension questions, which could not be answered by only remembering the text verbatim. One question referred to spatial information; the other two were related to nonspatial events (for sample questions, see the Appendix).
Narrative versions with change of direction. The narratives used in this condition were identical to those described above, with the only exception being that the underlying movement patterns involved a change of direction in the protagonist's path (Figure 2, right panel). For example, the protagonist started off from the experiment room and moved counterclockwise through the reception room and the adjacent office into the library. Then, the protagonist crossed through the inner courtyard diagonally. In the lounge, he or she changed direction and proceeded clockwise through the workshop into the store (see Figure 2, right panel). This movement pattern was also rotated by $90^{\circ}$ three times, yielding four different movement patterns. Thus, narratives containing a change of direction differed from those without a change in only two sentences. For example, in texts representing the movement patterns depicted in Figure 2, the third motion sentence read either "On her way to the store, she didn't notice anything unusual" or "On her way through the inner courtyard to the lounge, she didn't notice anything unusual." The second difference appeared in the fourth (second critical) motion sentence, which read either "Then she went from the store into the lounge" or "Then she went from the lounge into the store." All the other sentences were identical in both versions.

Filler texts. Eight filler texts of the same length and of comparable content and complexity as the experimental narratives were created. They differed from the experimental texts in that they did not adhere strictly to the pattern of critical motion sentences and target sentences used for constructing the experimental texts. Four filler texts were presented together with the no-change-of-direction experimental texts; these did not contain any changes of direction either. The remaining four filler texts were presented together with the change-of-direction experimental texts; these contained at least one change of direction.

Cognitive ability tests. Two scales of the IST-2000 (Intelligence Structure Test 2000; Amthauer, Brocke, Liepmann, \& Beauducel, 1999) were used to assess the participants' verbal and visuospatial abilities. The Analogies scale, consisting of 20 verbal analogies to be completed by the participant, was used as an indicator of verbal abilities. For instance, the item "small: large = short: ?" requires the participant to realize that "small" is the opposite of "large" and to respond with "long" because it is the opposite of "short." Solving analogies requires representing the meaning of concepts and their interrelations. Thus, high performance in this task indicates verbal abilities required for the construction of an exact propositional representation of the text's meaning. The Figure Selection scale, also consisting of 20 items, was used as an indicator of visuospatial abilities (see Figure 3 for sample items). In each of the figure selection
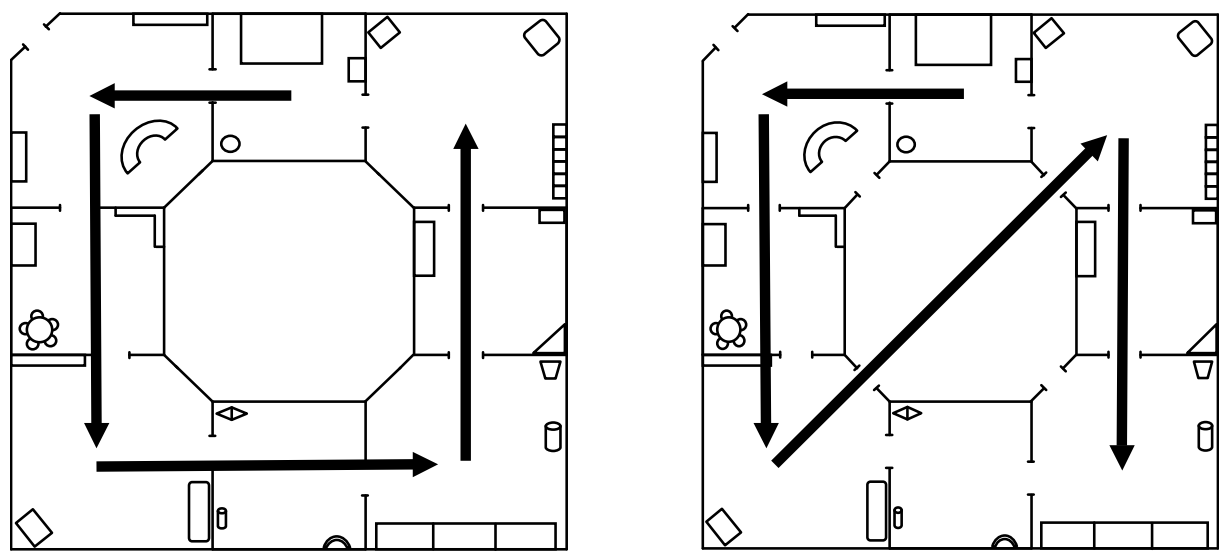

Figure 2. Movement pattern without (left) and with (right) change of direction. Each pattern was rotated three times by $9^{\circ}$, providing four patterns with and four patterns without change of direction. 


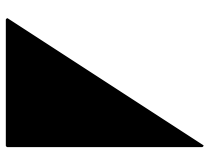

a
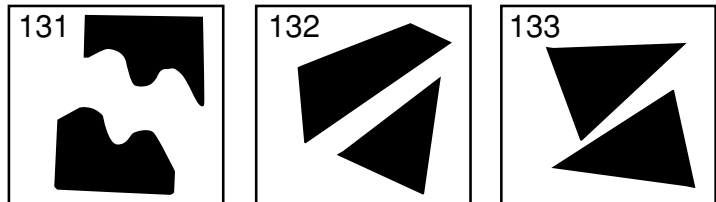

Figure 3. Sample test items of the Figure Selection scale of the IST-2000 (Intelligence Structure Test 2000; Amthauer et al., 1999). For each of Test Items 131-135, participants have to determine whether its parts can be arranged so that it represents one of Target Figures a-e. items, participants have to work out whether a set of irregular geometrical figures can be arranged so that it represents one of the target figures. This process requires that they mentally rotate and rearrange the figures. High performance in this task indicates the visuospatial abilities required to map spatial relations onto the situation model. This ability reflects the more perceptual nature of spatial situation models, as opposed to the propositional nature of the text base. The reliability of these scales is acceptable (Cronbach's $\alpha=.72$ and .78 for analogies and figure selection, respectively); their correlation is moderate $(r=.33)$

\section{Procedure}

All the participants were tested individually for about $80 \mathrm{~min}$. They first studied the layout of the research center at their own pace. When they felt that they were able to reproduce the layout, including all the rooms, doors, and objects, they completed a blank layout. After comparing it with the original layout, they studied it again and filled out another blank layout. This procedure was repeated until the participants made fewer than two errors in completing the layout. Then the participants read a practice narrative presented sentence by sentence on a computer screen. There were two versions of the practice text (with change vs. without), and each participant received the version that matched the participant's experimental texts.

Reading was self-paced: After reading a sentence, the participants pressed the space bar to call up the next sentence. The experimenter illustrated the protagonist's route described in the sample passage by drawing it into the layout of the building. At the end of the practice text, the participants answered three comprehension questions. The experimenter provided feedback about the correctness of the responses and answered questions about the experimental procedure. Then the participants read the eight experimental and four filler narratives in random order and at their own pace. The participants were instructed to read the texts at their habitual reading speed to understand the contents, but not to memorize the text verbatim. Instructions emphasized the importance of taking breaks between the narratives only, and not during reading. Depending on the experimental condition, the experimenter also mentioned that all the narratives would describe protagonists who never changed direction of movement or who always changed directions in unpredictable ways.

After each narrative, three comprehension questions were given in random order. No feedback was provided. After reading the 12 narratives, the Analogies scale and the Figure Selection scale were administered. Finally, the participants were debriefed and paid.

\section{Design}

A mixed factorial design was used with movement direction (changing vs. not changing) as a between-participants factor and spatial distance (anaphor referent in the path room vs. in the source room) as a within-participants factor. An additional betweenparticipants factor was created by splitting each movement direction group at the median of the verbal ability score or the spatial ability score into a low-ability subgroup and a high-ability subgroup (see below). Reading times for each sentence were measured in milliseconds and divided by the number of syllables in the sentence. Within each participant, reading times per syllable for each sentence were averaged across sentences of the same type: (1) motion sentences that described motions of the protagonist in the building, (2) critical motion sentences that described motions followed by a target sentence, (3) path room sentences (i.e., target sentences referring to an anaphor referent in the path room of the critical motion), (4) source room sentences (i.e., target sentences referring to an anaphor referent in the source room of the critical motion), and (5) noncritical sentences (i.e., all sentences of a narrative except for the first and the last and those belonging to Sentence Types 1-4). To correct reading times for outliers, reading times in each of these categories that deviated more than three standard deviations from the mean reading time for the given type of sentence were eliminated $(M=1.56 \%$, ranging from $0.52 \%$ to $2.34 \%$, depending on the type of sentence). This correction was performed separately for each participant and for each type of sentence.

\section{Results}

The scores on the cognitive ability scales were in the range expected for the sample's reference group. On a standard intelligence scale, the scores for the analogies task (verbal ability) ranged from 85 to $124(M=100)$, and the scores for the figure selection task (visuospatial ability) ranged from 88 to $125(M=103)$. The correlation between the scales was $r=.24$. The raw values of both scales did not differ between the group reading change-ofdirection narratives and the group reading no-change narratives [analogies, $F(1,47)=1.23$, n.s.; figure selection, $F(1,47)<1]$. Sample statistics for the median-split groups are given in Table 1. Dividing the participants according to verbal ability yielded a median split that was different from that for the division according to visuospatial ability: Of the 48 participants, 30 were grouped identically as low or high in ability, whereas 18 changed grouping.

The participants studied the layout for about $12 \mathrm{~min}$ to reach the learning criterion $(M=731 \mathrm{sec}, S D=171)$. Learning time did not differ between the change and the 
Table 1

Sample Statistics of the Verbal and Visuospatial Ability Scores After Median Split

in Experiments 1 and 2

\begin{tabular}{|c|c|c|c|c|c|c|c|c|}
\hline & \multicolumn{8}{|c|}{ Median-Split Groups } \\
\hline & \multicolumn{4}{|c|}{ Verbal Ability } & \multicolumn{4}{|c|}{ Visuospatial Ability } \\
\hline & \multicolumn{2}{|c|}{ Low } & \multicolumn{2}{|c|}{ High } & \multicolumn{2}{|c|}{ Low } & \multicolumn{2}{|c|}{ High } \\
\hline & No Change & Change & No Change & Change & No Change & Change & No Change & Change \\
\hline \multicolumn{9}{|c|}{ Experiment 1} \\
\hline$M$ & 11.0 & 11.67 & 14.83 & 15.83 & 10.92 & 10.83 & 15.25 & 16.67 \\
\hline$S D$ & 1.41 & 1.83 & 2.08 & 1.03 & 1.44 & 1.89 & 1.71 & 1.76 \\
\hline$n$ & 12 & 12 & 12 & 12 & 12 & 12 & 12 & 12 \\
\hline \multicolumn{9}{|c|}{ Experiment 2} \\
\hline$M$ & 11.67 & 11.17 & 15.58 & 15.33 & 10.33 & 11.5 & 15.83 & 17.33 \\
\hline$S D$ & 1.23 & 1.75 & 1.24 & 1.44 & 2.01 & 2.07 & 2.21 & 1.07 \\
\hline$n$ & 12 & 12 & 12 & 12 & 12 & 12 & 12 & 12 \\
\hline
\end{tabular}

Note-Raw values in the Analogies scale (Verbal Ability) and in the Figure Selection scale (Visuospatial Ability) of the IST-2000. The participants read texts in which the protagonist changed his or her movement direction (Change) or did not (No Change).

no-change groups or between participants with high versus low ability, verbal or spatial.

The narratives were well understood, with the percentage of correctly answered comprehension questions ranging from $75 \%$ to $100 \%(M=94 \%)$. As a check of success in counterbalancing the text materials, two ANOVAs were computed, with text set as an independent variable and reading times for noncritical sentences and target sentences as dependent variables. Text set did not have an effect on the reading times for noncritical sentences or target sentences [both $F \mathrm{~s}(7,40)<1$ ]. Analyzing reading times for noncritical sentences as a function of change of direction and of cognitive abilities did not yield any effects either.

Reading times for target sentences were subjected to two ANOVAs with spatial distance (anaphor referent in path room vs. source room), change of direction (yes vs. no), and verbal or visuospatial ability (low vs. high) as factors. In the first analysis (with verbal ability as an individualdifference factor), spatial distance had a significant main effect on reading times $\left[F(1,44)=8.85, M S_{\mathrm{e}}=1,889, p<\right.$ $.01]$, with path room sentences being read more quickly $(M=297, S D=86)$ than source room sentences $(M=$
$323, S D=114$; see also Table 2 ). A second main effect indicated that target sentences were read more slowly when the narratives involved a change of movement direction (path, $M=325, S D=83$; source, $M=353, S D=120$ ) than when they did not (path, $M=268, S D=80$; source, $M=293, S D=100)\left[F(1,44)=4.49, M S_{\mathrm{e}}=17,443\right.$, $p<.05]$. However, these main effects were qualified by a three-way interaction of spatial distance, change of direction, and verbal ability $\left[F(1,44)=9.51, M S_{\mathrm{e}}=1,889\right.$, $p<.01]$. To facilitate the interpretation of this interaction, we computed the differences between the reading times for source room sentences and the reading times for path room sentences. A positive difference indicated the magnitude of the spatial distance effect - that is, an increase of anaphor resolution time related to the increase of spatial distance between the reader's focus of attention and the location of the anaphor referent. Low-ability participants showed a large spatial distance effect in narratives without change of movement direction (Figure 4, left side), which was significantly larger than the minimal effect in narratives with change of movement direction $[t(22)=2.12$, $p<.05]$. High-ability participants showed the reverse relationship. Here, a large distance effect was found in

Table 2

Mean Reading Times per Syllable (With Standard Deviations; in Milliseconds) for Target Sentences in Experiments 1 and 2

\begin{tabular}{|c|c|c|c|c|c|c|c|c|c|c|c|c|c|c|c|c|}
\hline & \multicolumn{16}{|c|}{ Direction of Movement } \\
\hline & \multicolumn{8}{|c|}{ No Change } & \multicolumn{8}{|c|}{ Change } \\
\hline & \multicolumn{4}{|c|}{ Verbal Ability } & \multicolumn{4}{|c|}{ Visuospatial Ability } & \multicolumn{4}{|c|}{ Verbal Ability } & \multicolumn{4}{|c|}{ Visuospatial Ability } \\
\hline & \multicolumn{2}{|c|}{ Low } & \multicolumn{2}{|c|}{ High } & \multicolumn{2}{|c|}{ Low } & \multicolumn{2}{|c|}{ High } & \multicolumn{2}{|c|}{ Low } & \multicolumn{2}{|c|}{ High } & \multicolumn{2}{|c|}{ Low } & \multicolumn{2}{|c|}{ High } \\
\hline & $M$ & $S D$ & $M$ & $S D$ & $M$ & $S D$ & $M$ & $S D$ & $M$ & $S D$ & $M$ & $S D$ & $M$ & $S D$ & $M$ & $S D$ \\
\hline \multicolumn{17}{|l|}{ Experiment 1} \\
\hline Path room & 260 & 83 & 277 & 79 & 305 & 68 & 232 & 76 & 338 & 89 & 311 & 78 & 319 & 90 & 330 & 80 \\
\hline Source room & 306 & 115 & 281 & 86 & 345 & 90 & 241 & 84 & 332 & 99 & 373 & 140 & 331 & 86 & 374 & 148 \\
\hline \multicolumn{17}{|l|}{ Experiment 2} \\
\hline Path room & 260 & 78 & 243 & 61 & 265 & 75 & 238 & 62 & 320 & 99 & 227 & 71 & 274 & 74 & 274 & 118 \\
\hline Source room & 283 & 61 & 274 & 81 & 283 & 59 & 274 & 82 & 371 & 84 & 298 & 95 & 343 & 68 & 325 & 119 \\
\hline
\end{tabular}

Note-The participants read texts in which the protagonist changed his or her movement direction (Change) or did not (No Change). 
narratives with change of direction, but not in narratives without change, again yielding a significant difference between the two text types $[t(22)=2.66, p<.05]$.

The second analysis, with visuospatial ability as an individual-difference factor and spatial distance and change of direction as experimental factors, yielded qualitatively similar effects. Spatial distance had a significant main effect on reading times $\left[F(1,44)=7.66, M S_{\mathrm{e}}=\right.$ $2,184, p<.01]$, with path room sentences being read more quickly than source room sentences (see the means above and in Table 2). A second main effect indicated that target sentences were read more slowly when the narratives involved a change of movement direction than when they did not [see the means above and in Table 2; $\left.F(1,44)=5.29, M S_{\mathrm{e}}=15,144, p<.05\right]$. Although the three-way interaction of spatial distance, change of direction, and visuospatial ability was only marginally significant $[F(1,44)=2.74, p=.10]$, the means of the spatial distance effect showed a pattern very similar to that in the first analysis (Figure 4, right side).

In the preceding analyses, the cognitive ability variables were used to split the sample at the median so that groups of individuals with relatively high and low abilities could be compared. However, since dichotomization might be associated with a loss of information (Cohen, 1983), it is also useful to explore the interaction effect described above in terms of correlational relationships. Indeed, in the change-of-direction condition, correlations between cognitive ability variables and magnitude of the spatial distance effect were positive, whereas in the no-change condition, they were negative. The correlation between verbal ability and the spatial distance effect in the changeof-direction condition $(r=.43)$ differed significantly ( $z=2.73, p=.01$, one-tailed) from the corresponding correlation in the no-change condition $(r=-.36)$. Like- wise, the correlation between visuospatial ability and the spatial distance effect in the change-of-direction condition $(r=.26)$ differed significantly $(z=2.11, p=.05$, one-tailed) from the corresponding coefficient in the nochange condition $(r=-.40)$. Thus, the results of the correlational analyses, taking the complete variability of the ability scores into account, converged with the results of the ANOVAs based on the median split of the same scores. Moreover, highly comparable results were also observed in the analyses of partial correlations: Even after controlling for the effects of visuospatial ability, the positive correlation between verbal ability and the spatial distance effect in the change-of-direction condition (partial $r=.39$ ) differed significantly ( $z=2.34, p=.01$, one-tailed) from the corresponding negative correlation in the no-change condition (partial $r=-.30$ ). Similarly, after controlling for the effects of verbal ability, the positive correlation between visuospatial ability and the spatial distance effect in the change-of-direction condition (partial $r=.18$ ) differed significantly ( $z=1.79, p=.05$, one-tailed) from the corresponding negative correlation in the no-change condition (partial $r=-.35$ ).

The general hypothesis that decreased predictability of the protagonist's motions will increase the distance effect was corroborated by data from the participants with high verbal (and to a smaller extent, high visuospatial) ability, but not by data from the low-ability participants. Above, we argued that decreased predictability requires intensified integration of spatial text information into the situation model and that this intensified processing can be assumed to increase the relative strength of the situation model. Thus, relative to low-ability readers, high-ability participants' reading behavior should show signs of increased integrative processing in the change-of-direction condition. Indeed, evidence in favor of this hypothesis

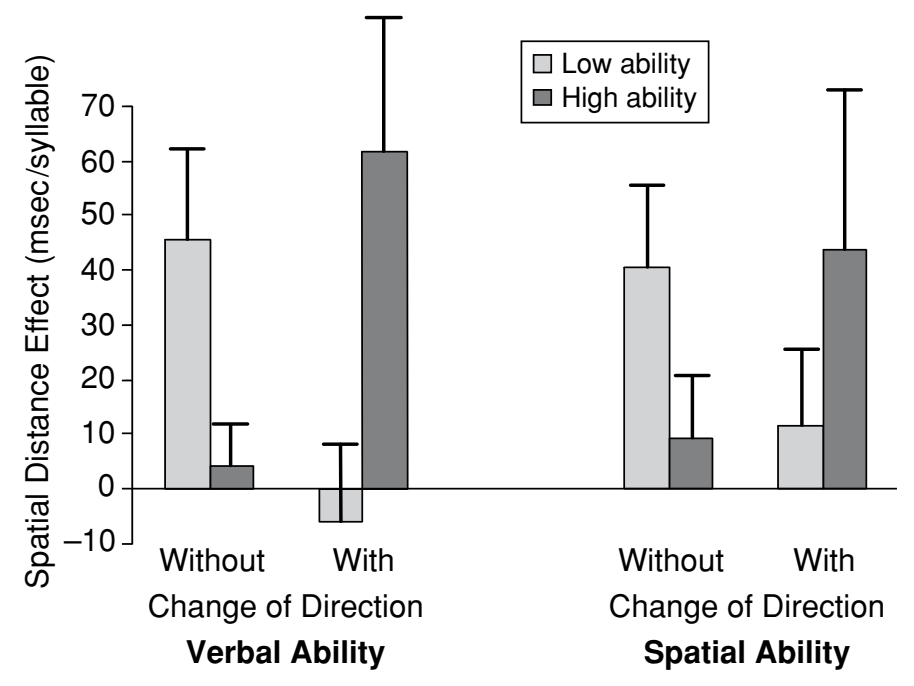

Figure 4. The spatial distance effect as a function of verbal and visuospatial ability and change of direction (Experiment 1). Error bars represent the standard errors of the means (these are relevant only for comparisons of the two groups with each other). 
was found in the reading times for the motion sentences. The participants with high verbal ability allocated more reading time to critical motion sentences in the change condition $(M=371 \mathrm{msec} /$ syllable, $S D=129)$ than in the no-change condition $(M=262 \mathrm{msec} /$ syllable, $S D=71)$ $[t(22)=2.57, p<.05]$. The same pattern was shown by the participants with high visuospatial ability. They allocated more reading time to critical motion sentences in the change condition $(M=349 \mathrm{msec} /$ syllable, $S D=109)$ than in the no-change condition $(M=236 \mathrm{msec} / \mathrm{syllable}$, $S D=63)[t(22)=3.09, p<.01]$. Since the critical motion sentences were almost identical in both conditions, the difference in reading time may be attributed most plausibly to deeper integrative processing on the situation model level caused by decreased predictability. Lowability participants did not show such a difference [low verbal ability, with change of direction, $M=317, S D=$ 77 ; without change, $M=276, S D=77 ; t(22)=1.29$, n.s.; low visuospatial ability, with change, $M=338$, $S D=111$; without change, $M=301, S D=70 ; t(22)=$ 0.99 , n.s.]. In other words, low-ability participants allocated about the same reading time to the critical motion sentences, irrespective of how easily the protagonist's motions could be anticipated. Comparing high-ability with low-ability participants separately within the change and no-change conditions yielded no significant differences. However, high-ability readers in the change condition spent more time reading critical motion sentences than did those in the three other groups averaged [verbal ability, $t(46)=2.80, p<.01$, one-tailed; visuospatial ability, $t(46)=1.78, p<.05$, one-tailed].

\section{Discussion}

In the present experiment, the magnitude of the spatial distance effect (Rinck \& Bower, 1995) was used as an indicator of the relative strength of the situational representation that readers create during reading. The situation model's relative strength was expected to increase with decreased predictability of the protagonist's motions. Data from the participants with cognitive abilities above the median corroborated this hypothesis. For narratives in which the protagonist changed his or her direction of movement unpredictably, a distance effect emerged. In contrast, in narratives in which the protagonist always moved in the same direction, the difference in reading times for source and path room sentences did not deviate from zero, indicating that an integrated spatial situation model may be lacking. Analyses of the reading times for motion sentences suggested that the increased distance effect may be due to deeper integrative processing on the situation model level when the text contains insufficient information to predict the protagonist's motions. In the no-change condition, however, the high-ability readers allocated less reading time to (critical motion) sentences that described the path along which the protagonist moved through the building. In this condition, it was easy to anticipate the protagonist's motions; therefore, situation model construction required less processing effort. Consequently, the situation model did not outweigh the text representa- tion with regard to its influence on anaphor resolution. In other words, the spatial distance effect vanished because, relative to the readers' verbal and spatial abilities, the demands of integrating text-independent knowledge into the situation model were low.

The low-ability participants showed the reverse pattern of reading times, with the magnitude of the distance effect decreasing in response to low predictability. In contrast to the high-ability readers, they did not allocate more time to representing the protagonist's route when the predictability of his or her movements was low. Because of this lack of integrative processing, spatial distance lost its influence on anaphor resolution. In this case, the spatial distance effect did not emerge, because, relative to the readers' verbal and visuospatial abilities, the demands of integrating the protagonist's route into the situation model were too high. In the no-change condition, however, even the low-ability readers succeeded in constructing a sufficiently valid and strong situation model. As a consequence, spatial distance affected anaphor resolution; that is, a spatial distance effect appeared.

\section{EXPERIMENT 2}

In Experiment 1, a spatial distance effect was not observed in two conditions. As was expected, the highability participants in the no-change condition showed no distance effect, because there was no need for them to further elaborate the situation model. Unexpectedly, the low-ability participants in the change condition did not show a distance effect either, probably because they lacked the cognitive abilities required to elaborate the situation model sufficiently. This interpretation was tested in the second experiment. The basic idea was to facilitate the participants' monitoring of the protagonist's path through the fictitious research center. To this end, the critical motion sentences were modified so that they mentioned not only the source room and the goal room, but also an object in the (as yet unmentioned) path room. Since the location of the path room object is known from initial layout learning, mentioning this object should provide an additional cue about the route the protagonist is taking through the building. The availability of this cue should support the low-ability participants in keeping up with the protagonist's motions. For the high-ability participants, however, this cue was not expected to represent any particular advantage, because (1) they had no problems in representing the protagonist's route even without this cue and (2) mentioning a path object does not provide any information beyond representing the route. It should be noted that the aim of this manipulation was to ensure that the readers would keep track of the protagonist's previous and current motions, but it was independent of the change-of-direction factor, whose aim was to manipulate the predictability of the protagonist's next motion(s). Thus, facilitating comprehension of the critical motion sentences did not change the predictability of the protagonist's next motions. Therefore, this manipulation was not expected to affect the general hypothesis pursued in this study, and we still expected 
spatial distance effects to be more likely to emerge under conditions of reduced predictability. However, the extra information about the current motion should enable the low-ability participants to elaborate their situation models sufficiently, even in the change-of-direction condition. Thus, the main hypothesis was that helping the readers to keep track of the protagonist's current location should attenuate the effects of individual differences in verbal and visuospatial abilities, so that all the participants would show larger spatial distance effects when future motions of the protagonist were less predictable.

\section{Method}

\section{Participants}

Forty-eight students (26 women) at the University of Kaiserslautern participated in this experiment. All the participants were native speakers of German or spoke German fluently. Their ages ranged from 18 to 33 years $(M=25)$. They received a payment of $€ 7.50$ for participating. In addition, they could earn a bonus of up to $€ 3$, depending on the number of comprehension questions answered correctly.

\section{Materials, Procedure, and Design \\ The same narratives as those in Experiment 1 were used, with a single modification: The second and fourth motion sentences (criti- cal motions) were revised so that they mentioned an object in the path room ("The protagonist went from the [source room] to the [goal room] passing the [object in path room]"). The path room itself was not mentioned. The path room object was recruited from Object Set 3 - that is, from the pool of objects that were not used as ana- phor referents. The layout of the fictitious research center, the com- prehension questions, the filler narratives, and the cognitive ability scales remained unchanged. The procedure and the experimental design were also identical to those in Experiment 1.}

\section{Results}

The scores on the ability scales did not differ from those in the first experiment. Standard intelligence scores for the Analogies scale ranged from 85 to $120(M=101)$, and those for the Figure Selection scale ranged from 88 to $125(M=104)$. The correlation between the two scales was $r=.25$. Neither variable differed between the experimental groups [analogies, $F(1,47)<1$; figure selection, $F(1,47)=1.79$, n.s.]. For sample statistics of the mediansplit groups, see Table 1. As in Experiment 1, the median splits according to verbal ability versus visuospatial ability differed: Of the 48 participants, 30 were grouped identically as low or high in ability, whereas 18 changed grouping. The percentage of comprehension questions answered correctly ranged from $81 \%$ to $100 \%(M=93 \%)$. Before analyses of reading times, outliers were eliminated. On average, $1.7 \%$ of the data points were identified as outliers and were eliminated (range, 1.3\%-2.08\%). Text set had no effects on reading times for noncritical sentences $[F(7,40)=1.04$, n.s. $]$ or target sentences $[F(7,40)<1]$. Likewise, analyzing reading times for noncritical sentences as a function of change of direction and cognitive abilities yielded no effects.

The participants memorized the layout for about $11 \mathrm{~min}$ to reach the learning criterion $(M=693 \mathrm{sec}, S D=172)$. Learning time did not differ between the change and the no-change groups or between participants with high versus low ability, verbal or spatial.

Reading times for target sentences were subjected to an ANOVA with spatial distance (anaphor referent in path room vs. source room), change of direction, and verbal or visuospatial ability as factors. In the first analysis, using verbal ability as an individual-difference factor, spatial distance had a significant main effect on reading times $\left[F(1,44)=24.65, M S_{\mathrm{e}}=1,844, p<.001\right]$, indicating that path room sentences were read more quickly $(M=263$, $S D=84)$ than source room sentences $(M=306, S D=$ 87 ; see also Table 2 ). Although only marginally significant, there was a general trend toward longer reading times when the narratives involved a change of movement direction (path, $M=274, S D=96$; source, $M=334$, $S D=95$ ) than when they did not (path, $M=251, S D=$ 69 ; source, $M=278, S D=70)\left[F(1,44)=3.38, M S_{\mathrm{e}}=\right.$ $10,859, p=.07]$. The interaction of spatial distance and change of movement direction was also marginally significant $\left[F(1,44)=3.65, M S_{\mathrm{e}}=1,844, p=.06\right]$. Figure 5 (left side) shows that the spatial distance effect tended to be higher in narratives involving a change of movement direction than in narratives with no change in direction. In fact, the effect size of the spatial distance effect was three times larger in the with-change-of-direction condition $\left(\eta^{2}=.52\right)$ than in the without-change-of-direction condition $\left(\eta^{2}=.17\right)$.

The second analysis, in which visuospatial ability was used as an individual-difference factor, yielded similar results. Spatial distance had a significant main effect on reading times $\left[F(1,44)=24.87, M S_{\mathrm{e}}=1,827, p<.001\right]$, indicating that path room sentences were read more quickly than source room sentences (see the means above and in Table 2). Again, the interaction of spatial distance and change of movement direction was marginally significant $\left[F(1,44)=3.69, M S_{\mathrm{e}}=1,827, p=.06\right]$, indicating that the spatial distance effect tended to be higher in narratives involving a change of movement direction than in narratives with no change in direction (Figure 5, right side).

The modification of the critical motion sentences was expected to attenuate the effects of individual differences in cognitive abilities on the spatial distance effect. In fact, these effects vanished completely: The three-way interaction terms involving verbal or visuospatial ability had $F$ values lower than 1.2. The correlations between magnitude of the distance effect and cognitive ability were zero or near zero, and they did not differ between the change condition (verbal, $r=.02$; visuospatial, $r=-.006$; both n.s.) and the no-change condition (verbal, $r=.18$; visuospatial, $r=.11$; both n.s.). Analyses of partial correlations revealed very similar results: Even after controlling for the potential effect of visuospatial ability, verbal ability did not correlate significantly with the spatial distance effect in the change condition (partial $r=-.02$ ) or the nochange condition (partial $r=.15$ ), and the two conditions did not differ significantly from each other either. The same was true for the partial correlations of visuospatial ability and spatial distance effect in the change condition 


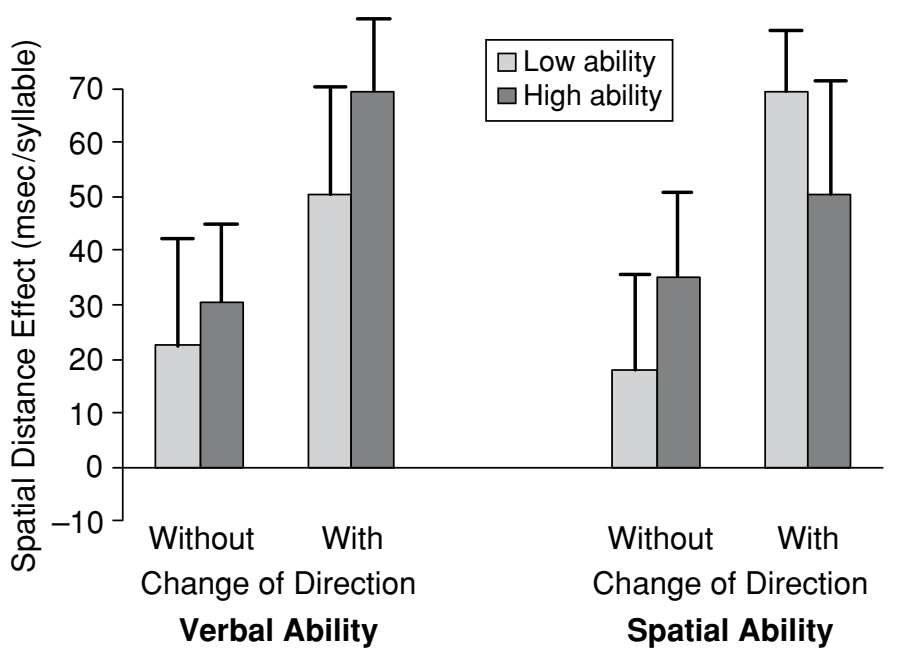

Figure 5. The spatial distance effect as a function of verbal and visuospatial ability and change of direction (Experiment 2). Error bars represent standard errors of the means (these are relevant only for comparisons of the two groups with each other).

(partial $r=-.01$ ) and the no-change condition (partial $r=.20$ ), after controlling for verbal ability.

Consistent with the increased spatial distance effect in the change condition and our interpretation that this was due to deeper integration of spatial information, the critical motion sentences were read for a longer time in the change condition $(M=321 \mathrm{msec} /$ syllable, $S D=88)$ than in the no-change condition $(M=260 \mathrm{msec} /$ syllable, $S D=62)[t(46)=2.77, p<.01$, one-tailed $]$.

\section{Discussion}

The most striking difference between the first and the second experiments is that the spatial distance effect pattern in low-ability participants was reversed. In the first experiment, low-ability participants showed no distance effect in the change condition; in the second experiment, they did. We attribute this reversal to the modified critical motion sentences. Presumably, mentioning a path room object helped the readers to keep track of the current motion and location of the protagonist. Generally, both ability groups in both conditions seemed to benefit from this manipulation: In each of the four groups, the magnitude of the spatial distance effect increased slightly, in comparison with the first experiment. To some extent, this may have been due to generally shorter reading times for the modified path room sentences. However, the low-ability participants showed a disproportionately large increase of the distance effect in the with-change-of-direction condition. In fact, comparing the four groups across the experiments, it was only in this combination (low ability/with change) that significantly different means between the experiments were observed [low verbal ability, $t(22)=-2.26, p<.05$; low visuospatial ability, $t(22)=-3.16, p<.01]$. Although comparisons across experiments have to be evaluated with caution, it is informative that analyzing the magnitude of the spatial distance effect in the low-ability participants as a function of change of direction (yes vs. no) and experiment (critical motion sentences without path room object vs. with path room object) yielded a significant interaction effect of change of direction and experiment [low verbal ability, $F(1,44)=4.75, M S_{\mathrm{e}}=4,023, p<.05$; low visuospatial ability, $\left.F(1,44)=6.84, M S_{\mathrm{e}}=2,855, p=.05\right]$. Facilitated parsing of the critical motion sentences thus compensated for the low-ability participants' processing limitations. As a result, variations in the predictability of the protagonist's motions affected the strength of their situation model in the same way as in the high-ability participants. Easily predicted protagonist motions now diminished the spatial distance effect in high- and low-ability groups. Enhanced knowledge of the protagonist's current motion and location is probably a precondition for anticipating future motions, but at the same time, it is independent of the predictability manipulation.

\section{GENERAL DISCUSSION}

In two experiments, the magnitude of the wellestablished spatial distance effect (Rinck \& Bower, 1995) was used as an indicator of the relative strength of the spatial situation model that readers create during the reading process. We found that in almost all the experimental conditions of the two experiments, the spatial distance effect was positive and that in some conditions, it was quite large, in comparison with earlier studies (e.g., Rinck \& Bower, 1995). This finding indicates that the readers created spatial situation models that were more influential than the effects of surface priming: On average, objects located in the unmentioned path room were more accessible than objects in the explicitly mentioned source room. More important, however, the spatial distance effect de- 
pended on the predictability of the protagonist's motions and, in Experiment 1, on the interaction of predictability and cognitive abilities.

The role of cognitive abilities was studied by comparing participants with low verbal and visuospatial abilities with participants with high abilities. Spatial predictability was manipulated by presenting texts in which all the protagonists (1) moved through a fictitious building without ever changing direction or (2) moved through the building changing direction in ways difficult to predict. As a result, a strong interaction was found in Experiment 1: The highability readers showed a spatial distance effect when the protagonist's motions were hard to predict and no distance effect when the motions were highly predictable, whereas the opposite was true for the low-ability readers. In Experiment 2, comprehension of the protagonist's current motion was facilitated by mentioning objects along his or her path. Although this did not make future motions more predictable, it did facilitate integrative spatial processing, compensating for the low-ability participants' processing limitations. As a result, variations in the predictability of the protagonist's motions affected the strength of the lowability participants' situation models in the same way as that for the high-ability participants. The latter participants' reading time patterns remained unaffected by mentioning the path room object because, even without this object, they had no problems representing the protagonist's current route. Furthermore, mentioning or not mentioning a path room object does not change the predictability of the future motions of the protagonist. Thus, in both ability groups, easily predicted protagonist motions now diminished the spatial distance effect. Consistent with our interpretation, easily predicted protagonist motions also diminished the reading time allocated to critical motion sentences.

Taken together, these results parallel those of McNamara and her colleagues (e.g., McNamara, 2001; McNamara \& W. Kintsch, 1996; McNamara et al., 1996). Texts requiring more intensive integration of text information and world knowledge may lead to a deeper understanding and to more valid and more easily available situation models. However, our results extend these findings in three directions. First, although the demands in our texts were different for anticipating where the protagonist would move, the with-change-of-direction texts and the without-change texts were equally coherent. We did not compare "good" expository texts with "bad" ones, but equally good narrative texts making different demands on the processing of spatial information. Nevertheless, the same effect of strengthening the situational representation appeared. Second, in the present study, the interactive effects of reader abilities and text characteristics can be clearly located at the situation model level, because they affected the spatial distance effect, the size of which may be taken as an indicator of situation model updating during narrative comprehension. Third, the earlier results, as well as ours, revealed strong interindividual differences. However, in earlier studies with expository texts, the reader-text interactions were due mainly to different knowledge levels, whereas in the present study with narrative texts, qualita- tively similar interactions were obtained by focusing on differences in verbal and spatial abilities. The results corroborate the position that more demanding texts may lead to more accurately updated situation models.

The present results also shed light on the relative importance of different cognitive abilities for the creation and updating of spatial situation models. We found that verbal abilities and visuospatial abilities predicted the spatial distance effect in similar ways and independently of each other. Both abilities were only moderately correlated in our sample, and the correlations between either of them and the spatial distance effect did not change when the influence of the other ability was controlled for. This is compatible with the view that these abilities contribute to the construction of different representations. Verbal abilities may be expected to affect completeness and coherence of the propositional text base, whereas visuospatial abilities may be expected to affect the mapping of propositionally represented spatial relationships onto the situation model (e.g., Friedman \& Miyake, 2000).

However, the lack of differentiation between those abilities may also be related to a levels-of-measurement problem. These ability measures were conceptualized as general purpose measures, and they do not specify the type of cognitive processes involved. As situation-unspecific resources, they may be generally related to situation model construction, although their differential functions cannot easily be identified. In future research, we will attempt to isolate the role of verbal abilities and visuospatial abilities by studying four extreme groups of participants varying in both abilities (low-low, low-high, high-low, and high-high).

An important point was also made by Radvansky and Copeland $(2001,2004)$, who found that working memory measures, although generally related to language processing, were unrelated to updating of spatial situation models. They pointed out that more situation-specific information-processing skills may yield more precise relations. In line with this reasoning, Radvansky and Copeland (2001) found that participants who scored higher on their Situation Identification Test updated situation models more successfully. The Situation Identification Test requires participants to select, from a list of six similarly formulated sentences, the one sentence that most closely matches the situation described in an initially presented target sentence. Recognizing a sentence as referring to the same situation as another, differently formulated sentence is a process-specific skill in creating and updating situation models. In line with Radvansky and Copeland's $(2001,2004)$ reasoning, our results encourage us to consider more process-specific skills in exploring individual differences in situation model updating, rather than general purpose abilities. This will also be an important topic for future research.

The lack of spatial distance effects in two of the four conditions in Experiment 1 (low abilities and low predictability, high abilities and high predictability) raises the question of how these null results relate to earlier findings and replications of the spatial distance effect on anaphor 
resolution (e.g., Rinck \& Bower, 1995; Rinck et al., 1997; Rinck et al., 1996). On the face of it, the results reported here seem to contradict the earlier reports of reliable spatial distance effects. Upon closer inspection, however, it turns out that the results are quite compatible. Earlier studies employed a mixture of narratives with or without changes in movement direction, thus varying in the degree of predictability. Moreover, the verbal and visuospatial abilities of the participants were not assessed; thus, it seems reasonable to assume that the samples contained a mixture of low-ability and high-ability participants. Across the experimental conditions of Experiment 1, a mean spatial distance effect of $26 \mathrm{msec}$ per syllable was found. As it turns out, this fairly small effect is quite similar to those observed in many earlier studies when reading times for source room sentences were compared with reading times for path room sentences (e.g., Rinck \& Bower, 1995). In fact, the reliable spatial distance effect replicated in many previous studies was due mainly to a location effect: Objects located in the same room as the protagonist were much more accessible than objects in any other room, whereas the difference between path room objects and source room objects was rather small and, often, only marginally significant. This is exactly what we would have found had we not differentiated between low- and high-ability participants, as well as between change and no-change narratives. Thus, overall, the results are not as discrepant as they may seem. Moreover, they demonstrate the importance of assessing individual differences in cognitive abilities: Joint analyses of all the participants would have obscured the present interactions completely and would have yielded the misleading conclusion that spatial distance effects are generally weak.

On the basis of the present pattern of results, we suggest that more attention should be paid to individual differences when text comprehension and situation models are studied. Interestingly, all but one of the numerous studies establishing and replicating the spatial distance effect have ignored the role of individual differences in the cognitive abilities required to construct an adequate situation model. The single exception was reported by Haenggi et al. (1995), who gave their participants a reading comprehension test, as well as tests of two-dimensional and threedimensional spatial imagery abilities. Afterward, their participants studied a map or a list of rooms and objects before reading narratives similar to the ones employed in our study. Unlike in our study, however, Haenggi et al. did not report effects of verbal abilities or visuospatial abilities on the spatial distance effect. Instead, they reported only main effects; that is, higher abilities were correlated with faster reactions overall. These results and other ones (e.g., de Vega, 1994) illustrate a recurrent problem associated with individual differences in text comprehension: Differences in verbal or visuospatial abilities have rarely been associated with qualitative differences in processing. Instead, they have often produced highly predictable and, therefore, potentially trivial main effects. The results of the present study are unusual in this respect, because differences in cognitive abilities yielded interactions with another variable - namely, predictability of motions.

\section{REFERENCES}

Amthauer, R., Brocke, B., Liepmann, D., \& Beauducel, A. (1999). Intelligenz-Struktur-Test 2000 [Intelligence Structure Test 2000]. Göttingen: Hogrefe.

Bereiter, C., \& Scardamalia, M. (1989). Intentional learning as a goal of instruction. In L. B. Resnick (Ed.), Knowing, learning, and instruction: Essays in honor of Robert Glaser (pp. 361-392). Hillsdale, NJ: Erlbaum.

Cohen, J. (1983). The cost of dichotomization. Applied Psychological Measurement, 7, 249-253.

DE VEGA, M. (1994). Characters and their perspectives in narratives describing spatial environments. Psychological Research, 56, 116-126.

Dutke, S. (1999). Der Crossover-Effekt von propositionaler Textrepräsentation und mentalem Modell: Zur Rolle interindividueller Fähigkeitsunterschiede [The cross-over effect of the propositional text representation and the mental model: Toward the role of individual differences in spatial imagery ability]. Zeitschrift für Experimentelle Psychologie, 46, 164-176.

DUTKE, S. (2003). Anaphor resolution as a function of spatial distance and priming: Exploring the spatial distance effect in situation models. Experimental Psychology, 50, 270-284.

Friedman, N. P., \& MiYake, A. (2000). Differential roles for visuospatial and verbal working memory in situation model construction. Journal of Experimental Psychology: General, 129, 61-83.

GARnHAM, A., \& OAKHILl, J. (1996). The mental models theory of language comprehension. In B. K. Britton \& A. C. Graesser (Eds.), Models of understanding text (pp. 313-339). Mahwah, NJ: Erlbaum.

Gernsbacher, M. A. (1990). Language comprehension as structure building. Hillsdale, NJ: Erlbaum.

Graesser, A. C., Millis, K. K., \& Zwaan, R. A. (1997). Discourse comprehension. Annual Review of Psychology, 48, 163-189.

Graesser, A. C., Singer, M., \& Trabasso, T. (1994). Constructing inferences during narrative text comprehension. Psychological Review, 101, 371-395.

Haenggi, D., Kintsch, W., \& Gernsbacher, M. A. (1995). Spatial situation models and text comprehension. Discourse Processes, 19, 173-199.

KINTSCH, E. (1990). Macroprocesses and microprocesses in the development of summarization skill. Cognition \& Instruction, 7, 161-195.

KInTsch, W. (1998). Comprehension: A paradigm for cognition. New York: Cambridge University Press.

Long, D. L., OpPy, B. J., \& Seely, M. R. (1997). Individual differences in readers' sentence- and text-level representations. Journal of Memory \& Language, 36, 129-145.

Mannes, S., \& Kintsch, W. (1987). Knowledge organization and text organization. Cognition \& Instruction, 4, 91-115.

McNamara, D. S. (2001). Reading both high-coherence and lowcoherence texts: Effects of text sequence and prior knowledge. Canadian Journal of Experimental Psychology, 55, 51-62.

McNamara, D. S., Kintsch, E., Songer, N. B., \& Kintsch, W. (1996). Are good texts always better? Interactions of text coherence, background knowledge, and levels of understanding in learning from text. Cognition \& Instruction, 14, 1-43.

McNamara, D. S., \& KinTsch, W. (1996). Learning from texts: Effects of prior knowledge and text coherence. Discourse Processes, 22, 247-288.

Radvansky, G. A., \& Copeland, D. E. (2001). Working memory and situation model updating. Memory \& Cognition, 29, 1073-1080.

Radvansky, G. A., \& Copeland, D. E. (2004). Working memory span and situation model processing. American Journal of Psychology, 117, 191-213.

Rinck, M., \& Bower, G. H. (1995). Anaphora resolution and the focus of attention in situation models. Journal of Memory \& Language, 34, 110-131.

RincK, M., Hähnel, A., Bower, G. H., \& Glowalla, U. (1997). The metrics of spatial situation models. Journal of Experimental Psychology: Learning, Memory, \& Cognition, 23, 622-637. 
Rinck, M., Williams, P., Bower, G. H., \& Becker, E. S. (1996). Spatial situation models and narrative understanding: Some generalizations and extensions. Discourse Processes, 21, 23-55.

Shah, P., \& Miyake, A. (1996). The separability of working memory resources for spatial thinking and language processing: An individual differences approach. Journal of Experimental Psychology: General, 125, $1-24$

VAn DiJK, T. A., \& Kintsch, W. (1983). Strategies of discourse comprehension. New York: Academic Press.
ZWaAn, R. A., \& BRown, C. M. (1996). The influence of language proficiency and comprehension skill on situation model construction. Discourse Processes, 21, 289-327.

Zwaan, R. A., Langston, M. C., \& Graesser, A. C. (1995). The construction of situation models in narrative comprehension: An eventindexing model. Psychological Science, 6, 292-297.

ZWAAN, R. A., \& RADVANSKY, G. A. (1998). Situation models in language comprehension and memory. Psychological Bulletin, 123, 162185 .

\section{APPENDIX \\ Sample Text for the No-Change-of-Direction Version (With Change-of-Direction Version in Parentheses) and Comprehension Questions}

\begin{tabular}{|c|c|}
\hline & $\begin{array}{l}\text { Ines worked very hard as head of research and expected others to do the same, } \\
\text { which didn't make her very popular. }\end{array}$ \\
\hline & $\begin{array}{l}\text { She had been receiving threatening letters for some time, but had interpreted them } \\
\text { as a feeble attempt to frighten her. }\end{array}$ \\
\hline \multirow[t]{3}{*}{ Location } & $\begin{array}{l}\text { One night she was working late in the experiment room, preparing an experiment } \\
\text { in the booth. }\end{array}$ \\
\hline & Suddenly, the noise of a door slamming made her stop and listen. \\
\hline & $\begin{array}{l}\text { At first she got angry, because she had dropped her instrument, but her anger } \\
\text { turned to fear when she remembered the mysterious threats she had been } \\
\text { getting. }\end{array}$ \\
\hline \multirow[t]{2}{*}{ Motion } & $\begin{array}{l}\text { Following the strange noise, Ines crept quietly into the reception room, hoping to } \\
\text { catch the intruder. }\end{array}$ \\
\hline & But there was no one to be seen. \\
\hline \multirow[t]{2}{*}{ Critical motion } & She then went from the reception into the library. \\
\hline & There she stood still for a moment, waiting for any more noises. \\
\hline Path room target & She thought she could hear a faint sound coming from the desk. \\
\hline Source room target & $\begin{array}{l}\text { She thought she could hear a faint sound coming from the display case. } \\
\text { Ines was suddenly unsure whether she had really heard the noise or just } \\
\text { imagined it. }\end{array}$ \\
\hline \multirow[t]{2}{*}{ Motion } & $\begin{array}{l}\text { On her way to the store (through the central courtyard to the lounge), she didn't } \\
\text { notice anything unusual. }\end{array}$ \\
\hline & $\begin{array}{l}\text { For a moment she considered just dropping everything and going straight home, but } \\
\text { then she decided that she had to find out if there was anyone in the building. }\end{array}$ \\
\hline \multirow[t]{2}{*}{ Critical motion } & Then she went from the store (the lounge) into the lounge (the store). \\
\hline & $\begin{array}{l}\text { She wondered whether someone was lying in wait for her somewhere in the build- } \\
\text { ing, ready to pounce on her. }\end{array}$ \\
\hline Path room target & She heard a noise that seemed to be coming from the workbench. \\
\hline \multirow[t]{3}{*}{ Source room target } & $\begin{array}{l}\text { She heard a noise that seemed to be coming from the waste bin (from the } \\
\text { refrigerator). }\end{array}$ \\
\hline & Ines screamed out as she saw a dark figure moving toward her. \\
\hline & $\begin{array}{l}\text { "Ines, I've been looking for you all this time," said her colleague, Sven; "I thought } \\
\text { we were going to the late show at the cinema!" }\end{array}$ \\
\hline \multirow[t]{3}{*}{ Comprehension questions } & Did Ines fear that somebody wanted to assault her? \\
\hline & Did Ines receive threatening telephone calls? \\
\hline & Did Ines go into the reception room after she had heard the slamming doo \\
\hline
\end{tabular}

Note-Each participant read either the change or the no-change versions of all the texts and either the path room target sentence or the source room target sentence of a particular target sentence pair. After each text, three comprehension questions were presented in random order, and the participant answered them by pressing one of two keys, labeled "yes" or "no." The original materials were written in German. 